\title{
A Arqueogenealogia Foucaultiana como lente para a análise do Governo da Língua Portuguesa no Brasil: continuidades e disrupções
}

\author{
Foucault's Archeogenealogy and analysis of the Portuguese Language Government \\ in Brazil: continuities and disruptions
}

\author{
Ivânia dos Santos NEVES \\ Universidade Federal do Pará \\ http://orcid.org/0000-0002-6738-5254 \\ Maria do Rosário GREGOLIN \\ Universidade Estadual Paulista - UNESP \\ https://orcid.org/0000-0002-9025-6733
}

\begin{abstract}
RESUMO: Adotando a perspectiva arqueogenealógica de Michel Foucault, este artigo se debruça sobre as estratégias de governamentalidade que institucionalizaram a língua portuguesa como um saber-poder que se instala ao longo da história colonial do Brasil. Focalizamos, particularmente, dois prolongamentos descontínuos nessa história: a) do momento inicial de nossa colonização, com o ensino jesuítico, ao século XVIII e a promulgação do Diretório dos Índios; b) do período Imperial à instalação da República (ao longo do século XIX e início do $X X)$. Não se trata, aqui, de compreender a língua apenas como estrutura linguística ou gramatical, mas sim de investigar suas estratégias muitas vezes belicosas, sua materialidade e sua indissociabilidade do exercício dos poderes. A língua, dessa perspectiva, envolve o corpo e suas formas de vida num espaço biopolítico de disputa de poder. Ao mostrar como o corpo foi investido de poder no decorrer da história brasileira, nosso objetivo é verticalizar a história tácita das políticas linguísticas no Brasil para além de leis ou decretos, compreendendo-a com suas normalizações insuspeitas, em seus cotidianos espaços de poder. Nosso olhar acompanha, na descontinuidade histórica, diferentes estratégias utilizadas pelo Dispositivo Colonial que subalterniza saberes e cosmologias e alimenta as desigualdades por meio da denegação de acontecimentos históricos. Entendemos essa intensa movimentação como o governo da língua, que é exercido por meio de vários dispositivos de saber e de poder articulados (religioso, jurídico, escolar, político-administrativo etc.) e que produz as linhas de força do quem somos e quem não somos nós hoje.
\end{abstract}

Palavras-chave: Arqueogenealogia; Dispositivo Colonial; Governo da Língua; História Brasileira.

ABSTRACT: Taking Michel Foucault's archeogenealogy as a theoretical and methodological framework, this article focuses on the governmentality strategies that institutionalized the Portuguese language as a knowledge-power that is installed throughout our colonial history in Brazil. In particular, we focus on two discontinuous extensions in this story: a) from the initial moment of our colonization, with Jesuit teaching, to the 18th century and the promulgation of the Directory of Indians; b) from the Imperial period to the installation of the Republic (throughout the 19th and early 20th centuries). Here, it is not a matter of understanding language only as a linguistic or grammatical structure, but of investigating its bellicose strategies, its materiality and its inseparability from the exercise of powers. The language, from 
this perspective, involves the body and its forms of life in a biopolitical space of power dispute. By showing how the body was invested with power throughout Brazilian history, our goal is to verticalize the tacit history of linguistic policies in Brazil beyond laws or decrees, understanding it with its unsuspected normalizations, in its everyday spaces of power. Our perspective accompanies, in the historical discontinuity, different strategies used by the colonial device that subordinates knowledge and cosmologies and feeds inequalities through the denial of historical events. We understand this intense movement as the government of the language, which is exercised through various articulated knowledge and power devices (religious, legal, school, political-administrative, etc.) and that produces the lines of force of who we are and who we are not today.

Keywords: Archeogenealogy; Colonial Device; Language Government; Brazilian History.

\title{
A arqueogenealogia de Michel Foucault como método e atitude teórica para o estudo dos discursos
}

\author{
Ay kakyri tama \\ Ynu tama verano y tana rytana \\ Ruaia manuta tana cultura ymimiua \\ Sany may-tini, iapá iapuraxi tanu ritual \\ Márcia Kambeba
}

A recepção da obra de Michel Foucault, por sua natureza interdisciplinar, envolve diferentes campos de saber e, com frequência, ainda que nem sempre de forma pacífica, ela convida para dialogar em eventos acadêmicos, em bancas de defesas ou em projetos de pesquisa, filósofos, historiadores, jornalistas, psicanalistas, juristas. Os três deslocamentos metodológicos delineados por ele, a arqueologia do saber, a genealogia do poder e a genealogia da ética representam outra peculiaridade de sua obra e também desafiam os arrumados lugares das ciências humanas no Ocidente. Por tantas inquietações e singularidades, no século XXI, independente do campo de atuação, cada vez mais pesquisadoras e pesquisadores interessados em problematizar a temporalidade, a verdade, a produção de saberes e poderes, os efeitos da biopolítica, as estratégias de um Estado racista passaram a tomar seus livros, seus ditos e escritos como referências fundamentais.

No Brasil, as pesquisas dedicadas aos estudos do discurso, na área de Letras, como indicam as bases de dados de Teses e Dissertações da Capes, "As Palavras e as Coisas" (1966/2005), “A Arqueologia do Saber" (1969/2004) e "A ordem do Discurso" (1970/2000) representam algumas das principais referências teórico-metodológicas

\footnotetext{
1 / essa cidade também é nossa aldeia/ não apagamos nossa cultura ancestral/ Vem, homem branco, vamos danças nosso ritual (Ay kakyri tama Eu moro na cidade KAMBEBA, 2018, p.24).
} 
deste campo. São obras cujas leituras se irradiaram pelo Brasil, sistematicamente, depois do declínio da última ditadura militar (1964-1985), sobretudo a partir das atividades desenvolvidas a princípio pelo GEADA - Grupo de Análise do Discurso de Araraquara, agora presentes nas referências de grupos de pesquisas espraiados por todas as regiões do país. Em 2018, a fundação do Grupo de Trabalho Estudos Discursivos Foucaultianos na ANPOLL começou a reunir estes grupos e a desenhar uma cartografia destes estudos no Brasil, com todas as suas singularidades.

Em 2019, a comemoração de 50 anos da publicação de “A Arqueologia do Saber", organizada por esse grupo, razão desse dossiê, significou também um momento de olharmos para os caminhos percorridos pelos estudos discursivos foucaultianos no Brasil. O livro "A Arqueologia do Saber" é essencialmente metodológico e se propõe explicitar o método utilizado em seus livros anteriores - "História da Loucura", "Nascimento da Clínica" e "As palavras e as Coisas", a fim de definir os fundamentos da proposta arqueológica e constituir princípios para a análise dos discursos no interior de arquivos. Dentre os principais elementos arqueológicos destaca-se o pressuposto de que os sujeitos são constituídos pela linguagem, atravessados pela descontinuidade histórica e pela produção de verdades e, para compreender essa fabricação das representações subjetivas é necessário tomar os saberes como o campo próprio da investigação. Nestes livros, mesmo estando subjacente às discussões, não encontramos, de forma sistematizada, uma analítica do poder.

O método arqueológico se instituiu como a base principal das pesquisas desenvolvidas na área de Letras no Brasil, no entanto, o amadurecimento dos grupos de investigação e as condições de possibilidades da atualidade, gradativamente, começaram a colocar em evidência a perspectiva arqueogenealógica. Michel Foucault não empreendeu reflexões específicas sobre o que seria um método arqueogenealógico, nem mesmo se utilizou desta denominação. Em língua portuguesa, esta definição foi usada pela primeira vez em 1993, pelo pesquisador português da área de comunicação Antônio Fernando Cascais, com o objetivo de especificar os deslocamentos metodológicos propostos por Foucault depois de sua fase arqueológica. Pela própria complexidade de suas formulações, sempre críticas a binarismos, não podemos ver uma dicotomia entre estas duas perspectivas, e embora se estabeleçam deslocamentos, há também entre elas uma relação de complementaridade.

A arqueogenealogia mantém a estrutura do método arqueológico, preocupado em assinalar as regularidades e as dispersões do discurso numa história descontínua, 
comprometido com a problematização da verdade, mas novos conceitos foucaultianos vão se somar às análises, no sentido de fazê-las avançar e passar de uma arqueologia do saber, para uma arqueogenealogia do saber-poder. Nesta passagem, as práticas discursivas podem ser tomadas como estratégias de governamentalidade, a ordem do discurso passa a ser compreendida também como processos de normalização e dispositivos de poder e saber, as políticas que envolvem o corpo ganham centralidade nas análises dos enunciados.

Essas transformações nas direções de suas análises são apresentadas por Foucault já na Aula Inaugural ministrada no Collège de France, em dezembro de 1970, publicada posteriormente com o título "A Ordem do Discurso". Nessa belíssima Aula, depois de apresentar os procedimentos desenvolvidos socialmente para o controle da produção e circulação de discursos, Foucault indica os caminhos que pretende trilhar a partir daí. Esse é um dos motivos que levam os estudiosos a enxergarem "A Ordem do Discurso" como um limiar, um momento de passagem da arqueologia para a arqueogenealogia foucaultiana.

Esse caminho teórico-metodológico baseia-se em duas atitudes: a crítica e a genealogia. A crítica segundo Foucault (1996, pag. 69-72) liga-se aos sistemas de recobrimento dos discursos, seus princípios de reordenamento, de exclusão e de rarefação. Trata-se, portanto, de investigar os procedimentos (discursivos e não discursivos) que controlam o que se pode e se deve dizer em um certo momento histórico. O segundo movimento - genealógico - propõe esquadrinhar a formação efetiva dos discursos - que é, ao mesmo tempo, dispersa, descontínua e regular - em suas relações com os saberes e os poderes.

Essas duas direções de pesquisa se complementam e indicam como o discurso continua a ser uma categoria fundante de todo o pensamento foucaultiano, conceito central para pensar as subjetividades, os saberes e os poderes. A empresa a ser desenvolvida nas décadas de 1970 e 1980 reforça essa proposição arqueogenealógica. Podemos tomar, por exemplo, as conferências realizadas no Rio de Janeiro no início dos anos 1970 e posteriormente publicadas em livro com o título "A verdade e as formas jurídicas" (FOUCAULT, 2003) e atestar a força que ainda é atribuída às práticas discursivas e não discursivas. Já na primeira conferência ministrada na UFRJ, Foucault assinala que suas investigações articulam três principais eixos de pesquisas:

1. A história dos domínios de saber em relação com as práticas sociais: para Foucault, é preciso perguntar quais as condições históricas e sociais que possibilitaram a 
formação de certos saberes como, por exemplo, no século XIX, sobre o homem, a partir da disjunção entre normal e anormal. Esses saberes foram fabricados por práticas discursivas (como os relatórios médicos) e por práticas não discursivas (como as práticas sociais de controle e vigilância nos hospícios, nas prisões, nas escolas etc.);

2. A análise do discurso como jogo estratégico e polêmico: O segundo eixo de pesquisa é metodológico, denominado análise dos discursos e inspirado na filosofia analítica anglo-americana de Searle e Austin e seus continuadores. Foucault propõe, nesse eixo, tratar "os fatos de discurso não mais simplesmente sob seu aspecto linguístico mas como jogos, jogos estratégicos, de ação e de reação, de pergunta e de resposta, de dominação e de esquiva, como também de luta. O discurso é esse conjunto regular de fatos linguísticos em determinado nível, e polêmicos e estratégicos em outro.” (2003, p. 9). A partir da leitura de Nietzsche, a genealogia foucaultiana entenderá discurso de maneira próxima aos sofistas, isto é: ele tem materialidade e é um jogo estratégico indissociável do exercício do poder (FOUCAULT, 2003, p. 149-150);

3. Uma reelaboração da teoria do sujeito: Ponto de convergência entre os outros dois eixos, consiste em uma reelaboração da teoria do sujeito. Segundo Foucault, é preciso realizar - a partir de Nietzsche - uma crítica radical do sujeito humano pela história; pensar em um sujeito que não é dado a priori, mas que se constitui no interior mesmo da história e que é a cada instante fundado e refundado pela história (2003, p. 10).

Esses três eixos subsumem o princípio de que, para Michel Foucault, a genealogia é uma atitude filosófica que pressupõe a insurreição dos saberes dominados "contra a hierarquização científica do conhecimento e seus efeitos intrínsecos de poder" (FOUCAULT, 2007, p.172), já a arqueologia é um método de análise capaz de visibilizar as discursividades locais. Podemos então tomar a arqueogenealogia, como um referencial teórico, uma atitude analítica e ao mesmo tempo um método de análise.

As pesquisas na área de Letras que tomam a arqueogenealogia como referência teórico-metodológica começam a ampliar os objetos de análise. Num campo em que a análise da mídia impressa marcou decisivamente as primeiras pesquisas, agora, com frequência podemos encontrar a presença das audiovisualidades e muitas pesquisas realizadas na Web. Ganham relevância trabalhos voltados à educação, ao processo de colonização, a questões de gênero. Os diálogos intelectuais também começam a se pluralizar e se, a princípio, havia um predomínio de referências francesas, agora, escolas 
de pensamento latino-americano e neste universo pesquisadoras e pesquisadores brasileiros ocupam mais espaço nas discussões.

$\mathrm{Na}$ sintonia deste momento dos estudos do discurso foucaultianos, este artigo, tomando como referência a arqueogenealogia, se debruçou sobre as estratégias de governamentalidade que institucionalizaram a língua portuguesa como um saber-poder no Brasil, no período republicano. Não se trata de compreender a língua como estruturas linguísticas ou gramaticais, perspectiva tão duramente criticada por Michel Foucault em vários trabalhos, mas sim de mostrá-la com suas estratégias muitas vezes belicosas, que envolvem o corpo e suas formas de vida, num espaço biopolítico de disputa de poder.

Nosso interesse, ao mostrar como o corpo foi investido de poder ao longo de nossa colonização, foi verticalizar a história tácita das políticas linguísticas no Brasil para além de leis ou decretos, compreendendo-a com suas normalizações insuspeitas, em seus cotidianos espaços de poder. Da escola jesuítica ao Diretório de Pombal no período colonial, da criação dos grupos escolares e das escolas normais após Independência e sua ampliação na Primeira República, há uma história que subalterniza saberes e cosmologias, alimenta a diferença colonial e continua se atualizando de forma bastante potente. Entendemos essa intensa movimentação como o governo da língua.

Em trabalhos anteriores (GREGOLIN, 2000, 2015), (GREGOLIN; CORRÊA, 2016, 2017), (NEVES, 2009, 2015, 2020), (LISBOA; NEVES; GREGOLIN et alii, 2020), assim como em pesquisas que orientamos, o estudo das estratégias dos dispositivos para o governo da língua portuguesa já ganharam relevância, embora ainda não usássemos explicitamente essa relação (dispositivos/governo da língua) como categoria analítica. Neste artigo, demos continuidade a essas discussões, abordando o governo da língua em suas relações coloniais, na forma como suas estratégias envolvem o corpo e a língua a fim de produzir subjetividades. Procuramos mostrar como as linhas de enunciabilidades/visualidades, de força e de subjetividade da língua portuguesa interferem no quem somos e no quem não somos nós, hoje, no Brasil.

\section{O dispositivo colonial, os jesuítas e o governo da língua}

Como sabemos, Michel Foucault não abordou o conceito de dispositivo detalhadamente em seus livros, trata-se de uma definição apresentada em suas entrevistas e falas. Em "Sobre a história da sexualidade", ele sistematiza três facetas do dispositivo: primeiro, ele o caracteriza como um conjunto heterogêneo "que engloba discursos, instituições, organizações arquitetônicas, decisões regulamentares, leis, 
medidas administrativas, enunciados científicos, proposições filosóficas, morais, filantrópicas" (FOUCAULT, 1999, p. 244) e em seguida assinala que há sempre um certo tipo de jogo de poder entre esses elementos heterogêneos. Depois, chama atenção ao fato de que o dispositivo, em um determinado momento histórico, teve como objetivo principal responder a uma urgência e por isso ele tem uma função estratégica dominante (GREGOLIN, 2015).

Em linhas gerais, o conceito de dispositivo para Michel Foucault está relacionado à produção de saberes, poderes e subjetividades e sempre vai atender a emergências históricas. Dentro dos dispositivos, digladiam-se estratégias de imposição e de resistência, que podem se chocar, se camuflar e até mesmo convergir. Sem formas fixas, com frequência se atravessam uns com outros. Eles se atualizam, se reposicionam e normalizam o cotidiano de sujeitas e sujeitos que sequer suspeitam de seus contornos. Os dispositivos se inscrevem em redes de memórias, que cruzam o presente, o passado e o futuro.

O Dispositivo Colonial, com seus contornos permeáveis, está diretamente relacionado à colonização europeia, iniciada com as grandes navegações no final do século XV e mantido bem vivo na atualidade, com seus reposicionamentos e suas novas possibilidades históricas. Podemos pensá-lo como um programa empreendido, a princípio pelos europeus com seus interesses comerciais, militares e religiosos, mas que também foi assumido pelas elites locais dos países colonizados, tanto na América como em outros continentes. Nossa proposta é concebê-lo como uma arquitetônica global que funciona por meio da articulação de vários outros dispositivos. Assim, conforme vislumbraremos em nossas análises, o governo dos corpos e da língua foi e continua sendo, historicamente, exercido pelo Dispositivo Colonial através da rede de outros dispositivos, como o bélico- militar, o pedagógico, o religioso, o jurídico, o escolar, o midiático etc.

Desde cedo, ele respondeu à urgência das metrópoles europeias de controlar corpos e territórios de acordo com suas próprias cosmologias, que, naturalmente foram heterogêneas nestes mais de cinco séculos e nesta espacialidade planetária da empresa colonizadora. Sobretudo no início, a guerra pelas subjetividades foi imprescindível e a construção de tecnologias de poder para apagar as formas de vida dos povos colonizados representa sua face mais importante para cumprir sua função estratégica dominante (NEVES, 2009, 2015). 
De forma muito abrangente, podemos pensar em cinco grandes emergências históricas que constituem o Dispositivo Colonial na América Latina: a invasão dos primeiros colonizadores, espanhóis e portugueses, a forte presença inglesa, francesa, alemã e holandesa, os processos de independência política e seus desdobramentos, o imperialismo dos Estados Unidos, depois da Segunda Guerra e a chegada dos chineses embalada pela cultura da convergência midiática. Sem prescindir do agenciamento da palavra e dos seus rituais (mídia, escola, religião), todas elas se organizam a partir das realidades locais e são fortemente atreladas a interesses econômicos.

A historiografia brasileira tem se dedicado, com sucesso, aos aspectos administrativos, políticos e econômicos sem incorporar, no entanto, a trajetória histórica das línguas ou a evolução de suas funções como objeto de preocupação e de análise. As formas e as dificuldades de reprodução da língua portuguesa e das línguas indígenas em território brasileiro, e, sobretudo a situação de contato entre elas, também não mereceram uma atenção maior dos historiadores, para quem o tema não tem sido considerado relevante, embora sem ele não seja possível compreender o processo de interação conflituosa entre índios e colonizadores, ou revelar determinados componentes das matrizes formadoras da nacionalidade (BESSA-FREIRE, 2004, p.21).

A produção de verdades sobre os conflitos coloniais começou a se instituir desde a chegada das primeiras embarcações, nas cartas dos cronistas e nos textos produzidos pelos primeiros religiosos, com a palavra escrita em línguas europeias. Também foi necessário, em vários momentos da colonização encontrar formas de se relacionar com as sociedades indígenas, sem que necessariamente precisassem exterminá-las, era preciso se valer de tecnologias de poder para transformá-las. Nestas perspectivas, desde o início, o governo da língua e sua associação ao poder pastoral foram fundamentais para colocar em marcha o Dispositivo Colonial.

Na primeira metade do século XVI, a colonização portuguesa enfrentou muitas dificuldades para ocupar o que hoje compreendemos como território brasileiro e “civilizar” seus moradores nativos. Ecoava também na América a guerra religiosa promovida pela Reforma Protestante e pela Contrarreforma da Igreja Católica. A ameaça dos calvinistas franceses no litoral do Brasil e do Grão-Pará era constante, pois mantinham relações amistosas com os Tupinambá e pretendiam fundar no novo continente um país em que pudessem ter liberdade de religião.

A igreja católica sempre esteve presente na colonização ibérica, desde as primeiras conquistas na África, mas uma nova ordem foi fundada em 1534, por Inácio de Loyola, a Companhia de Jesus com o objetivo específico de instituir a fé cristã entre 
as populações colonizadas. A criação de escolas, a gramaticalização e a dicionarização das línguas nativas eram algumas das principais ações desses religiosos. Não por acaso esta congregação foi tão fortemente apoiada pela Corte portuguesa e encontrou nas escolas fundadas em Portugal seu principal centro irradiador de novos jesuítas.

Os jesuítas José de Anchieta, Antônio Nóbrega e Antônio Vieira, filhos da Contrarreforma, são alguns dos maiores expoentes da igreja católica no Brasil. Considerados protetores dos povos indígenas, os três ainda hoje são respeitados por sua produção literária, assumida pela crítica literária ocidental como uma espécie de precursora da literatura brasileira, e pouco se fala de como eles foram decisivos no processo de apagamento das cosmologias indígenas.

No Brasil, como em outras colônias, as populações indígenas foram agregadas em missões, onde foram criadas as escolas jesuíticas e todo um cotidiano pautado em novas práticas culturais. No trecho seguinte, em uma carta enviada à Companhia de Jesus, Nóbrega descreve seus objetivos:

A lei, que lhes hão-de-dar, é defender-lhes comer carne humana e guerrear sem licença do Governador, fazer-lhes ter uma só mulher, vestirem-se, pois tem muito algodão, ao menos depois de cristãos, tirar-lhes os feiticeiros, mantê-los em justiça entre si e para com os cristãos, fazê-los viver quietos sem se mudarem para outra parte, se não for para entre cristãos, tendo terras repartidas que lhes bastem, e com estes padres da Companhia para os doutrinarem (NOBREGA, Carta da Bahia, 08 de maio de1558).

José de Anchieta, embora tenha sido um dos principais responsáveis pelo genocídio dos Tupinambá, durante a Confederação dos Tamoios ${ }^{2}$, recentemente chegou a ser indicado para canonização em função do trabalho que realizou entre os Tupiniquim e Tupinambá. A ele se deve o primeiro estudo sistematizado e escrito de uma língua indígena no Brasil, "A Arte (gramática) da Língua mais usada na costa do Brasil”. Os três exemplos as seguir mostram como o jesuíta manipulava a tradução do Tupinambá para o português, atribuindo o discurso cristão à cosmologia destes indígenas:

$$
\text { Cosmologia Tupinambá Tradução de Anchieta }
$$

\footnotetext{
${ }^{2}$ Bem diferente do discurso estabilizado sobre a resistência indígena, que fala em índios pacíficos, que não resistiam, a história dos Tupinambá, já no primeiro momento da colonização, mostra que eles não aceitaram pacificamente a dominação, tampouco nutriram profunda admiração pela cultura ocidental, como afirmam muitos autores. Estes índios eram corajosos guerreiros, que apoiados pelos franceses, promoveram, liderados por Ambirê e Guaixará, no litoral dos estados do Rio de Janeiro e de São Paulo, entre 1554 e 1567, a Confederação dos Tamoios e levaram a guerra contra os portugueses às últimas consequências (NEVES, 2009, p. 61).
} 


$\begin{array}{ccc}\text { Tupã } & \text { ruídos da natureza, trovões } & \text { Deus-Pai do cristianismo } \\ \text { Anhangá } & \text { espíritos da floresta } & \text { Diabo } \\ \text { Ánga } & \text { princípio vital } & \text { Alma }\end{array}$

Não podemos ver como despretensioso o trabalho com as línguas indígenas realizado pelos jesuítas. A língua escrita e a descrição linguística registrada em suas gramáticas, seus dicionários, suas cartas e seus livros de poemas se inscrevem como a expressão da verdade divina a ser seguida.

A gramática do enunciado jesuítico implica, portanto, mapear o tupi e capturá-lo com classes e categorias gramaticais do latim, do português e do espanhol. Ao inseminar na língua tupi a presença de uma alma católica proporcionada pela semântica substancialista de uma memória de culpa, a gramática também produz seu análogo sensível, o corpo dócil, ordenado em práticas prescritivas que o integram juridicamente como inferioridade natural. Lição da Política aristotélica, é próprio do inferior subordinar-se naturalmente ao superior (HANSEN: 2005, p. 38).

A ação da catequese jesuítica, necessariamente, passou pela disciplinarização do corpo. Não existe o governo da língua sem que o corpo seja envolvido em um jogo de poder e arregimentado para dentro de uma nova ordem. A respeito desta espacialidade que envolve os corpos indígenas nas missões, Michel Foucault (2005, p.421) assim se pronuncia:

Penso também nas extraordinárias colônias de jesuítas fundadas na América do Sul: colônias maravilhosas, absolutamente organizadas, nas quais a perfeição humana era efetivamente realizada. [...] A aldeia era repartida segundo uma disposição rigorosa em torno de um lugar retangular no fundo do qual havia a igreja; de um lado, o colégio, de outro, o cemitério, e além disso, diante da igreja, se abria uma avenida que uma outra vinha cruzar em ângulo reto; as famílias tinham cada uma sua pequena cabana ao longo dos dois eixos, e assim se encontrava exatamente reproduzido o signo do Cristo.

Muito antes das modernas correntes teóricas dos estudos da linguagem e da comunicação, os jesuítas dominavam essas tecnologias relacionadas ao governo da língua. Eles dimensionavam o poder de conhecer e manipular as línguas das populações colonizadas e estiveram envolvidos na formação das línguas gerais forjadas em toda a América Latina. Ficaram tão poderosos que chegaram a desejar a criação de um Estado jesuítico no Novo Mundo.

Embora atendendo a emergências históricas diferentes, as ações jesuíticas foram delineadoras das primeiras e intensamente belicosas relações com as línguas indígenas e as línguas africanas nas duas colônias lusitanas na América, nos dois primeiros séculos. No início da colonização no Estado do Brasil, iniciada com a chegada de Martin Afonso 
de Sousa em 1532, na Capitania de São Vicente, a língua portuguesa ainda não havia se firmado, a partir dos critérios ocidentais, como uma língua autônoma, o que aconteceria apenas em 1580, com a publicação de "Os Lusíadas" de Luís de Camões. Também precisamos considerar o intenso intercâmbio cultural e linguístico entre esta colônia e as colônias lusitanas na África que aconteceram desde o início da colonização.

O Estado do Brasil, onde se desenvolvia o polo de produção escravista entretinha relações densas e regulares com os portos e enclaves portugueses na África, e principalmente com Angola. Neste sentido, a centralidade de Angola na história do Brasil é anterior à inserção da Amazônia no restante da América Portuguesa. (ALENCASTRO, p. $18,2009)$.

Em 1614, depois de superadas as demarcações impostas pelo Tratado de Tordesilhas, para conter a ação dos franceses na região, aconteceu a fundação de São Luís, primeira capital da segunda colônia lusitana na América, o Estado do Grão-Pará e Maranhão, que até a Independência do Brasil manteve relações diretas com Portugal. Neste período, o cenário cultural da língua portuguesa estava diferente, pois já havia uma produção literária consolidada como marco de identidade lusitana e pouco tempo depois, Gregório de Mattos Guerra daria início a um movimento literário em língua portuguesa, produzido no Brasil.

No período colonial, os missionários jesuítas agenciaram três Línguas Gerais envolvendo o português, línguas africanas, sobretudo a língua quimbundo do tronco linguístico banto e as indígenas do tronco tupi, especialmente o guarani e o tupinambá. Duas delas foram faladas no Estado do Brasil, a Língua Geral Paulista (base tupi) e a Língua Geral do Sul da Bahia (base banto), a terceira no Estado do Grão-Pará e Maranhão, a Língua Geral Amazônica (base tupi), ou o nheengatu.

Uma dessas línguas, o nheengatu, teve papel histórico marcante, como meio de comunicação interétnica, porque foi ela e não o português, a principal língua da Amazônia, presente nas aldeias, povoações vilas e cidades de toda a região. Durante dois séculos e meio, índios, mestiços, negros e portugueses trocaram experiências e bens, desenvolveram a maioria de suas práticas sociais, trabalhando, narrando, cantando, rezando, amando, sonhando, sofrendo, rindo e se divertindo nessa língua indígena que se firmou como língua supraétnica, difundida amplamente pelos missionários por meio da catequese (BESSA-FREIRE, 2004, p.17).

Ainda hoje, o nheengatu é falado por povos indígenas no interior da Amazônia. E, assim como a língua portuguesa, desde o início da colonização, passou por muitas transformações. Se a princípio representou a língua da catequese jesuítica, depois de tantos séculos de apropriação, hoje ele está associado às identidades indígenas. 
Devemos ver nos movimentos destas línguas e em seus agenciamentos políticos e econômicos uma intensa luta de fricção e de necropolítica linguística, que, embora administradas por tecnologias de governamentalidade da língua, muitas vezes foram definidas pelo poder da pólvora. O próprio enunciado línguas gerais já carrega em si uma posição discursiva, pois demarca um interesse colonial: a homogeneização das línguas e a produção da falácia do monolinguismo.

Depois de uma série de desencontros entre os interesses das metrópoles ibéricas e os movimentos empreendidos pelos jesuítas em suas missões na América do Sul, que sinalizavam para uma ruptura com Portugal e Espanha, em 1759, sob o comando de Marques de Pombal, eles foram expulsos das colônias portuguesas. Em 1755, para responder às atitudes dos religiosos, foi produzido um documento com 95 determinações sobre a administração das populações indígenas. O "Diretório dos Índios " $"$ traçou as novas diretrizes da política colonial e, depois da experiência com os jesuítas, nele vemos o reposicionamento da Coroa em relação ao governo da língua, como podemos observar em uma de suas primeiras deliberações:

6. Sempre foi máxima inalteravelmente praticada em todas as Nações, que conquistaram novos Domínios, introduzir logo nos povos conquistados o seu próprio idioma, por ser indisputável, que este é um dos meios mais eficazes para desterrar dos Povos rústicos a barbaridade dos seus antigos costumes; [...] Para desterrar esse perniciosíssimo abuso, será um dos principais cuidados dos Diretores, estabelecer nas suas respectivas Povoações o uso da Língua Portuguesa, não consentindo por modo algum, que os Meninos, e as Meninas, que pertencerem às Escolas, e todos aqueles Índios, que forem capazes de instrução nesta matéria, usem da língua própria das suas Nações, ou da chamada geral; mas unicamente da Portuguesa (grifo nosso).

Esta iniciativa de proibir as línguas indígenas aparece detalhada nas correspondências de Francisco Xavier de Mendonça Furtado (1758), irmão do Marques de Pombal e governador do Grão-Pará. Destacamos a seguir as instruções $3^{\circ}, 18^{\circ}$ e $22^{\circ}$ de uma diligência a ser realizada por ele na colônia:

$3^{\circ}$. Se falam a língua portuguesa: se já há alguns que saibam ler e escrever. [...]

\footnotetext{
${ }^{3}$ O Diretório dos Índios foi elaborado em 1755, mas só se tornou público em 1757. É um documento que expressa importantes aspectos da política indígena do período da história de Portugal e do Brasil denominado pombalino. Esse nome deriva do título nobiliárquico de Sebastião Joseph de Carvalho e Mello, Marquês de Pombal, poderoso ministro do rei de Portugal D. José I. Cf: < https://www.nacaomestica.org/diretorio_dos_indios.htm >
} 
$18^{\circ}$. De que nação se compõem a tal Aldeia? Qual era a sua língua natural? Em que tempo se estabeleceu? Donde vieram os moradores para aquele Sítio? Quem os persuadiu, e catequizou? [...]

$22^{\circ}$. Se a aldeia tem capacidade para se reduzir a Vila, e nesse caso se será mais útil juntar-lhe mais alguns moradores vizinhos, que não sejam índios, misturando todos no número dos que servirem no Senado, ou conservar à parte os mesmos Índios? (grifo nosso) (MENDONÇA, 2005, p. 411-414).

Governamentalidade, para Michel Foucault, representa, sobretudo as tecnologias de controle social. Quando observamos a movimentação dos jesuítas e depois da Coroa portuguesa em relação à administração das línguas faladas pelos povos indígenas, vemos como os diferentes interesses do Dispositivo Colonial afetaram a vida dessas populações, interferindo em seus territórios e suas práticas culturais.

\section{O governo da língua no Brasil imperial e seus desdobramentos na escola republicana}

A história colonial brasileira nos mostra que o governo dos corpos e das línguas é estratégico para o funcionamento do Dispositivo Colonial e é exercido por vários dispositivos, dentre eles o religioso, o pedagógico e o jurídico. Além desses dispositivos, cujos elementos são sistematizados por uma arquitetônica global (Deus; a Pedagogia, a Palavra; a Lei) há ainda outros, cujo funcionamento é mais difuso, mas que, entretanto, tem funções muito pragmáticas na vida social. Foi o que ocorreu após a chegada da família real portuguesa e sua corte ao Rio de Janeiro, em 1808, momento em que uma rede fluida, mas eficiente de elementos foi colocada em marcha e exerceu importante papel na fixação da língua portuguesa como língua de prestígio social.

Isso ocorreu, primeiramente, com a chegada de milhares de cortesãos junto com a realeza e que fez aumentar drasticamente o número de falantes de português no Brasil. Além disso, o estatuto de capital do Império fez com que o Rio de Janeiro impusesse grandes mudanças na cena cultural brasileira - com a criação da Imprensa e da Biblioteca Nacional - o que tornou a língua portuguesa um poderoso instrumento de comunicação, de inserção e de ascensão social. Usada a partir de então nos eventos da vida da corte, ela adquire prestígio, transforma-se em marca de civilidade e de nobreza social. Podemos dizer, em princípio, que funcionou aí toda uma rede de dispositivos ligados ao funcionamento administrativo nobiliárquico para o governo dos corpos (regras de etiqueta cortesã; rituais típicos da corte como o célebre "beija-mãos", etc.) e da língua (o português, como língua da corte, adquire status de nobreza e precisa ser 
regrado por meio de instrumentos como as gramáticas e dicionários para evitar a corrupção de sua "pureza").

Assim, funcionando concomitantemente com o dispositivo jurídico que proibira o uso de outras línguas (o Diretório de Pombal), a partir de agora a imposição da língua portuguesa será regrada também por normas sociais de prestígio. Qualquer cidadão que se expressasse fora das normas gramaticais do português seria, a partir daí, considerado inculto, incivilizado, de segunda categoria. A junção desses dois dispositivos pode sinalizar uma das razões para o desaparecimento da língua falada pelos caipiras, a Língua Geral Paulista, ao longo do século XIX ${ }^{4}$.

Dentre todos os dispositivos - que, evidentemente, estão sempre articulados uns aos outros - foi o dispositivo escolar aquele que adquiriu maior proeminência, a partir da Independência (1822), pois devido ao seu alcance e a sua abrangência social tornouse instrumento potencializado para a construção da identidade nacional. Certamente, a língua esteve no centro desse projeto nacional, como signo da civilidade e da modernidade do país independente, mas que manteve o regime monárquico, e, portanto, continuava fortemente ligado ao trono português.

O governo da língua portuguesa era complexo no período pós-Independência, expressando as contradições de nossa situação política. A monarquia com a permanência de um rei português em um país independente já era, por si, surpreendente. Os processos para a construção da nacionalidade brasileira foram também contraditórios e se basearam na edificação de um país e uma língua harmônicos. Após a Independência o debate sobre a língua nacional tornou-se tema de acirrados confrontos entre intelectuais e dirigentes imperiais que se sentiam incomodados com a denominação de língua portuguesa e propunham substitui-la por outras: língua brasileira, língua pátria, idioma nacional. Esse debate exibia as profundas contradições que alicerçavam nossa independência:

A preocupação com a língua nacional ligava-se ao problema da ordem social em uma sociedade escravista, atravessada por inúmeros conflitos políticos e sociais, pelos regionalismos e particularismos locais em um território que englobava forte diversidade cultural e étnica, e que afinal continha um grande número de habitantes que simplesmente comunicavam-se em outras línguas. Assim, no processo

\footnotetext{
${ }^{4}$ A Língua Geral Paulista, de base tupi, originou-se, já no século XVI, na região de São Vicente e alto do rio Tietê. Nos séculos XVII e XVIII foi levada pela ação das bandeiras paulistas para os estados de Minas Gerais, Goiás, Mato Grosso e norte do atual estado do Paraná. Os estudiosos consideram que seu desaparecimento se deu entre o século XIX e início do século XX (LEITE, 2013).
} 
de formação do Estado no Brasil, essa questão tinha um peso estratégico e ligado à soberania política. (LIMA; DO CARMO, 2008, p. 12)

Esse debate sobre a língua nacional torna evidente que a permanência de um rei português em um país independente trará uma série de consequências em relação ao que vimos denominando o governo da língua. Será necessário, nesse Primeiro Reinado, fortalecer a prevalência da língua portuguesa e a Escola foi responsável pela afirmação da língua do colonizador como língua nacional e, portanto, de prestígio. Assim, ao mesmo tempo em que se construiu a representação da importância das pessoas alfabetizadas em português, obliterou-se a importância das "outras" línguas - da população mais pobres (a língua geral dos caboclos e dos caipiras), dos indígenas, dos pardos e negros libertos ou escravizados. Apesar de contar com poucos estabelecimentos escolares, essa opção por denegar outras línguas em favor do ensino do português culto atesta que na nascente nação recém-independente já estava em curso um projeto nacional que previa a exclusão da cidadania de amplos setores e jogava a perspectiva de mudanças para um futuro longínquo e indeterminado (SCHWARCZ; STARLING, 2018, pag. 231-232).

A força do governo da língua se expande e se fortalece durante o Segundo Reinado, após a posse de D. Pedro II (1840). Imersa em muitas crises políticas e revoltas populares durante o período Regencial, a Monarquia estava frágil e a estratégia para fortalecê-la foi a construção da imagem de um monarca sábio, protetor das artes e das ciências. No seu longo reinado, D. Pedro II cercou-se de intelectuais a fim de promover a construção da ideia de nacionalidade por meio do estímulo às artes (literatura, teatro, pintura) e às ciências (botânica, geografia, história etc.). Tratava-se da continuidade do projeto de homogeneização linguística e cultural e, para isso, foi preciso ocultar a escravização dos negros e idealizar os indígenas que, dizimados sistematicamente nas florestas, apareciam heroicos nos romances, nas pinturas e no imaginário cívico. Conforme asseveram SCHWARCZ e STARLING (2018, pag. 284), “a representação do país como indígena (e masculino) juntava as concepções de um Brasil americano, mas também monárquico e português. Ou seja: uma mistura da velha metrópole com a identificação com a América, que nos fazia independentes."

Foi na área da literatura que o nacionalismo ganhou maior visibilidade, em obras cujos personagens são indígenas idealizados e construídos em língua portuguesa culta, como, por exemplo, em "Iracema" e "O Guarani", ambos livros de José de Alencar e publicados em 1865. Na pintura, cenas de bravura e heroísmo bélico constroem a 
narrativa de nossa história de lutas, como A Batalha de Avaí (Pedro Américo, 1877); A Batalha de Guararapes (Victor Meirelles, 1879) ou produzem a mítica encenação de nossa fundação na Primeira Missa no Brasil (Victor Meirelles, 1860).

Esse intenso movimento cultural e linguístico promovido pela Monarquia fortaleceu os liames entre nacionalidade brasileira e língua portuguesa e produziu a representação de qual deveria ser a boa língua para o povo: o português culto, escrito, gramaticalmente mais próximo possível de Portugal, apesar de admitirem-se certos laivos de origem indígena e africana na sua gramática, especialmente na fonética e no léxico. A admissão do dualismo entre o português de Portugal e o usado no Brasil será lenta e crescente desde o momento da Independência até o final do século XIX, quando alguns gramáticos começam a indicar diferenças de pronúncia, de construção sintática e de criação vocabular. Essas peculiaridades do português falado no Brasil, consideradas como "brasileirismos", aparece em várias gramáticas produzidas entre 1830 e 1890, como, por exemplo", na muito difundida "Noções de Grammatica Portugueza", de Pacheco da Silva Jr. e Lameira de Andrade, publicada em 1887:

O português fallado no Brazil diverge do falado em Portugal, não só, e mui principalmente, na pronuncia, mas também em algumas transferencias de significação [...]. O vocabulario é o mesmo, mais opulentado com o elemento tupyguarani, e mais alguns termos africanos. Devemos, porem, attender ás inevitaveis idiossyncrasias mentaes". (PACHECO; LAMEIRA, 1887, p. 510)

Ou, ainda, nos "Serões Gramaticais" de Carneiro Ribeiro, publicado em 1890:

Dentre os brasileirismos léxicos notam-se certos vocábulos tomados ás lingoas e aos dialectos americanos e africanos. Taes são os vocábulos: tapera, caipora, cacique, quilombo, quiabo [...] lundú, e os vocábulos de tratamento infantil nhonhô, nhanhan.” (CARNEIRO RIBEIRO, 1890, p. 533)

E na evidência da heterogeneidade na formação do vocabulário em português do Brasil, conforme assinala João Ribeiro, em sua "Grammatica portugueza: $3^{\circ}$ anno", publicada em 1887:

Quando porém, todos os elementos do composto são de origem extrangeira, nenhuma consciencia existe dos sentidos elementares do vocábulo. É o que succede com os termos: Redingote - Do inglez: riding coat; vestido para montaria. Charcuteria - Do francez: chaircuite. Carne cozida. Biscoito - Do latim: biscoctus. Duas vezes cozido. [...] Xará - Do tupi-guarani: Xe hera (absol, terá) meu nome. É um brazileirismo.” (RIBEIRO, (1889[1887], p. 74-75)

\footnotetext{
${ }^{5}$ Esses exemplos de três gramáticas foram colhidos no excelente trabalho de Historiografia Linguística realizado por FERREIRA COELHO; GABRIEL DANNA; POLACHINI, 2014.
} 
Pinto (1978) faz uma valiosa análise dessa paulatina consciência gramatical sobre o português do Brasil, apontando a heterogeneidade dos fatos linguísticos apresentados. Para a autora, essa heterogeneidade liga-se aos diferentes campos a que se dedicavam os intelectuais da época, com suas idiossincrasias e filiações filosóficas e políticas.

Não foi, entretanto, apenas nas páginas literárias, nas artes e nas gramáticas que se deu o governo da língua e da cultura no Segundo Reinado. A fim de destacar certa memória, reconhecer uma cultura e produzir um ambiente favorável à construção da nacionalidade, D. Pedro II impulsionou a criação do Instituto Histórico e Geográfico Brasileiro, sediado no Rio de Janeiro. Essa instituição, que congregava grandes intelectuais da época, tinha como um dos seus objetivos construir uma história nacional por meio da escolha de acontecimentos e personagens. Dentre os principais historiadores desse Instituto, destaca-se Francisco Adolfo de Varnhagen, especializado na escrita de biografias de nomes vultuosos da história brasileira; esse laivo de biógrafo aparecerá nos dois volumes de sua "História Geral do Brasil", publicados em 1854 e 1857.

Essa forte intervenção da literatura, das artes e da escrita da história no governo da língua encontrará no dispositivo escolar seu lugar de circulação e transmissão. Essa apropriação foi bastante alargada no final do século XIX, quando a recém proclamada República instalou um amplo dispositivo escolar nas capitais brasileiras e, com isso, aprofundou a representação de prestígio do letramento, isto é, da aquisição de uma competência social para o uso da língua portuguesa, tanto na oralidade quanto na escrita.

Gregolin (2015) discute a instalação do dispositivo escolar republicano em nosso país, a partir da análise de álbuns fotográficos da Escola Caetano de Campos, instalada na capital paulista em 1895, a fim de tornar-se modelo para a rede escolar que se ampliaria a todas as capitais brasileiras nos anos seguintes. Nesse artigo, por meio da análise de práticas discursivas escolares, Gregolin nos mostra que a Escola tradicional brasileira, em todos os seus elementos, é segregacionista, é um lugar em que a sociedade separa e exclui classes sociais, raças, etnias, gêneros. Do ponto de vista de sua visibilidade, as operações de exclusão podem ser verificadas em fotografias escolares brasileiras do começo do século XX, observando imagens das turmas de professores e alunos da Escola Normal Caetano de Campos. Observa-se, nessas fotografias uma iconografia de corpos brancos: não se vê nenhum professor/professora 
ou aluno/aluna indígena ou negro. Assim, apesar de representar-se como "uma escola para todos", ela apenas dá visibilidade a um imaginado Brasil, branco, civilizado e conforme as ideias eugenistas tão em voga naquele momento.

Do ponto de vista da sua enunciabilidade, a exclusão (étnica, de classe, de gênero...) tem como um dos principais operadores justamente o prestígio atribuído ao letramento, à apropriação da leitura e da escrita em língua portuguesa. Essa operação de exclusão, como vimos mostrando, vem desde os primeiros tempos de nossa colonização e - a despeito de certos momentos de suspensão, nos poucos e breves intervalos democráticos na história política do Brasil - vem sendo produzida, memorada e reforçada pela escola tradicional ao longo do tempo. Ao mesmo tempo em que se excluem sujeitos (por meio da seleção racial, étnica, de classe social) também são excluídas suas línguas e suas culturas do ambiente escolar. A Escola foi, certamente, um dos mais poderosos dispositivos a executar o projeto do Dispositivo Colonial de fixar o português como (aparentemente) a única língua do Brasil. Podemos ilustrar essa atitude discricionária que irá exercer o governo da língua, apontando algumas práticas da política republicana para a leitura e a escrita.

Em relação à escrita, alguns movimentos merecem ser destacados: os métodos de alfabetização, as técnicas da escrita manual e o ensino da caligrafia. Quanto à alfabetização, ocorreu um reordenamento das práticas pedagógicas para as séries iniciais que levou ao desenvolvimento de cartilhas. Nesse esforço, o método analítico de alfabetização tornou-se signo de modernidade e fez surgir muitos livros didáticos, inclusive uma "Coleção Caetano de Campos", desenvolvida por professores dessa instituição. O método analítico propunha uma didática racional para o ensino da escrita das primeiras letras, baseada em palavras e sílabas e se opunha ao antigo método sintético, que ensinava as letras:

Figura 01: Capa e página da Cartilha Analítica de Arnaldo Barreto, 1909. 


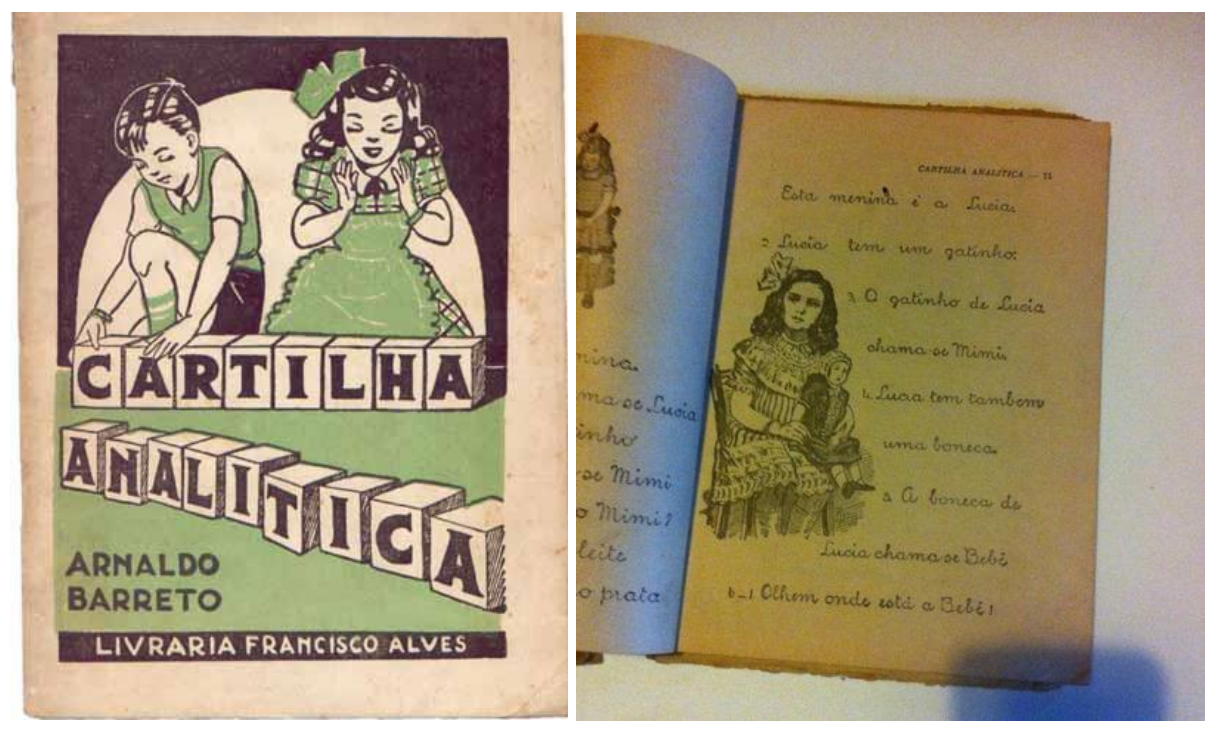

Fonte: Acervo do CRE Mario Covas, São Paulo, SP

Quanto à técnica da escrita, há um grande debate, logo após a instalação da República, sobre as vantagens da escrita vertical em relação à escrita inclinada, adotada até então. Essa discussão tinha em sua base preceitos higienistas muito respeitados naquele momento no Brasil republicano. Com base no discurso médico, a escrita inclinada era acusada de causar problemas de miopia e escoliose nos estudantes. Por isso, para manter a saúde dos alunos, a caligrafia vertical era indicada como a mais adequada ao trabalho escolar. Conforme assinala Vidal (1998, p. 1), "Papel direito, corpo direito, escrita direita pareciam resumir as prescrições da higiene". Além desse aspecto ligado à saúde, a escrita vertical era também associada à legibilidade e à simplicidade, o que levaria a uma regularização da letra manual, tornando-a mais homogênea e, portanto, preparando o aluno para o exercício de uma escrita eficiente e necessária para o trabalho (FARIA FILHO, 1998).

O projeto de homogeneização e regularização da escrita envolvia, também, o investimento no ensino das técnicas de caligrafia, que pressupunham a disciplina do corpo para a produção da escritura correta e bela. Esse ensino iniciava-se nos últimos anos do primário e estendia-se durante todo o secundário e exigia o disciplinamento do corpo para a produção da escrita. Tratava-se, portanto, de uma tecnologia de controle do sujeito aprendiz: por meio do governo do corpo, as técnicas caligráficas exerciam o governo da língua.

Vários foram os métodos e manuais desenvolvidos para esse fim e merece destaque o "Método de Caligrafia De Franco", de autoria de Antonio de Franco, que propunha "o ensino da técnica que proporciona ao aluno hábitos de ordem, asseio e disciplina mental e corporal". O governo do corpo para o governo da língua é explícito 
nesse manual que atribui o insucesso na aprendizagem da arte caligráfica às "más posições do corpo, braços e mãos, mui difíceis de ser corrigidas verbalmente" (DE FRANCO, 1915/1928, p. 23). Mais explicito ainda, o corpo torna-se o centro de uma engenharia cujo produto final deve ser a escrita perfeita, correta, bela. Juntam-se, na escrita caligráfica três elementos vitais para a ideologia republicana: a saúde e a educação estavam na base da plataforma política de que o progresso e a constituição da nação brasileira estavam assentados na higiene, na disciplina corporal e na alfabetização. Como concretização dessa ideologia e de uma forma de pensamento há décadas questionados, as rígidas regras dessa escrita são surpreendentes para nós hoje, desacostumados do manuscrito e imersos nos rituais da palavra digitalizada.

A profusão de cartilhas e de livros de caligrafia mostra que a República nacionalizou o ensino da língua materna (e de geografia e história) e, para isso, houve necessidade de nacionalizar o livro didático. Com o passar dos anos, eles foram incorporados de forma tão sólida à memória escolar coletiva brasileira que acabaram por constituírem-se em importantes instrumentos para a consolidação da ideologia republicana (GREGOLIN, 1988). É no âmbito da leitura escolar que se expressa de forma mais contundente essa nacionalização dos manuais, determinando a escolha de textos, autores e leitores e, portanto, fortalecendo a representação do prestígio social da língua por meio da leitura. Os materiais de leitura escolar ofereciam aos alunos conjuntos de textos em que se celebrava o nacionalismo, o ufanismo e o culto a um pretenso passado nacional glorioso. Na maioria das vezes, eles seguiam os preceitos da escrita da história preconizada por Varnhagen, na sua concepção de uma história geral como homenagem ao monarca de sua época (D. Pedro II).

Um exemplo desses livros didáticos utilizado durante décadas nas escolas paulistas é "Tradições Nacionais. Episódios Históricos e Brasileiros Notáveis”, de Gomes Cardim (1916, p. 3) $)^{6}$, em cuja apresentação o autor declara: “O principal escopo deste livro é fazer reviver os nossos feitos gloriosos, os grandes triumphos nos mares e em terra, bem como as nossas grandes conquistas nas sciencias, nas letras e nas artes".

Para realizar esse objetivo, Gomes Cardim reconta episódios da história brasileira com forte dose de conservadorismo e culto aos heróis pátrios. Evidentemente, a escolha das figuras heroicas segue o padrão da história oficial, particularmente

\footnotetext{
${ }^{6}$ Encontra-se a $1^{\text {a }}$ edição facsimilar em: http://lemad.fflch.usp.br/sites/lemad.fflch.usp.br/files/201901/tradicoesnacionais.pdf
} 
centrada em episódios bélicos e enaltecedores de grandes militares. Assim são narradas as guerras contra as invasões holandesa, inglesa e francesa e merece ênfase e destaque a Guerra do Paraguai (1864-1870), ainda muito vívida na memória coletiva. A narrativa dessa última guerra é emblemática: enaltecem-se os grandes heróis militares (Duque de Caxias, General Osório e outros) que com sua bravura enfrentaram e deram suas vidas para derrotar, escorraçar e executar o "tirano Lopes". Nenhuma palavra, entretanto, sobre os negros escravos que foram aos campos de batalha substituindo seus donos, com a promessa de alforria na volta. Nenhuma palavra sobre as insurreições populares que eclodiram durante o período Regencial e o Segundo Império (Cabanagem, Sabinada, Balaiada, Guerra dos Farrapos, Canudos etc.). Apenas oficiais brancos de alta patente são dignos desse panteão livresco da leitura escolarizada e cujo objetivo é despertar o sentimento cívico dos leitores.

Essas práticas discursivas da Escola Republicana aqui apontadas (métodos de alfabetização, técnicas de escrita caligráfica, leitura e apropriação da narrativa histórica ufanista) nos mostram como as estratégias do dispositivo escolar têm materialidade e são indissociáveis do exercício dos poderes. A língua, dessa perspectiva, envolve o corpo e suas formas de vida num espaço biopolítico de disputa de poder e por meio dela produzem-se a memória e os sentimentos coletivos.

\section{Considerações Finais}

$\mathrm{Na}$ diversidade de perspectivas metodológicas propostas por Michel Foucault, o conceito de dispositivo e as discussões sobre governamentalidade fazem parte das referências relacionadas à sua fase genealógica, quando ele formaliza seu interesse pela história dos saberes sujeitados e se volta para a biopolítica.

O corpo e o dispositivo são elementos centrais numa análise genealógica: o corpo como objeto, como produto e o dispositivo como modo de operação, de produção de verdades, de realidades, de sentidos, mas também de objetos, de corpos individuais e coletivos, de subjetividades e modos de vida concretos. Os dispositivos são também elementos fundamentais da política contemporânea, justamente pelos efeitos normalizadores, objetivantes e subjetivantes de suas ações, que acabam mobilizando resistências e enfrentamentos (PRADO FILHO, 2017, p.325).

As discussões sobre governamentalidade propostas por Foucault em seus cursos "Segurança Território, População" (janeiro a abril de 1978) e "Nascimento da Biopolítica" (1978/1979) mobilizam uma analítica do poder sobre as populações, procurando enxergar como elas podem ser controladas pelas estatísticas e submetidas a 
coerções tácitas ou não que se exercem no próprio corpo do indivíduo. Os processos de governamentalidade se estabelecem e se mantêm a partir de tecnologias de poder, que podem se mover para atender às transformações históricas, como vimos em relação à imposição das línguas gerais no período colonial e da língua portuguesa durante a Monarquia e na primeira fase de República.

O Dispositivo Colonial e sua arquitetônica rede de dispositivos, ainda que lentamente, também se reposicionam, se atualizam e produzem no interior de sua própria tessitura, possibilidades de resistência. Nesta perspectiva, não podemos desconsiderar que a história do governo das línguas é dinâmica e descontínua. Afinal, a conquista, por mais duradoura que seja é sempre provisória e neste início de século, alguns acontecimentos visibilizaram essa descontinuidade. Em 2003, pela primeira vez na história, contrariando a Constituição Brasileira que estabelece o português como única língua oficial do país, em São Gabriel da Cachoeira, no estado do Amazonas, três línguas indígenas, o tukano, o baniwa e o nheengatu, a partir de uma lei municipal, também passaram à condição de línguas oficiais da cidade.

Como culminância deste processo, iniciado e alimentado pelas reivindicações do movimento indígena, tramita atualmente na Câmara Dos Deputados, o Projeto de Lei N. ${ }^{\circ}$ 3.074-A, de 2019, do Sr. Dagoberto Nogueira, que dispõe sobre a Cooficialização das Línguas indígenas nos municípios brasileiros onde existam sociedades indígenas. E, por mais contraditório que possa parecer, durante o governo de Jair Bolsonaro, cuja posição em relação aos direitos indígenas é de extrema intransigência, este projeto recebeu parecer favorável da Comissão de Direitos Humanos e Minorias. Ainda há um grande percurso até que vire lei, inclusive pode receber veto presidencial, mas nunca as línguas indígenas estiveram tão próximas de alcançar legitimidade.

Essas movências históricas são exemplos das trajetórias das tantas línguas faladas neste território que hoje concebemos como Brasil. Elas interferiram decisivamente nas diferenças regionais dos padrões linguísticos do português brasileiro. É preciso refutar de uma vez por todas o discurso de que as línguas europeias são o destino natural da evolução humana, como acreditavam os evolucionistas. Todas as línguas são processos sociais, sempre inacabadas, imbricadas com formas particulares de vida, permeáveis às transformações históricas, portanto, imersas em jogos de poder. 


\section{Referências}

ALENCASTRO, Luiz Felipe de. Os africanos e as falas africanas no Brasil. In GALVES, Charlotte; GERMES, Helder; RIBEIRO, Fernando Rosa. África-Brasil: caminhos da língua portuguesa. Campinas: Editora Unicamp, 2009.

BARRET0, Arnaldo. Cartilha Analytica. Rio de Janeiro, São Paulo, Belo Horizonte Livraria Francisco Alves, 1909. 1a ed.

BESSA FREIRE, José Ribamar. 2003. Língua Geral Amazônica: a história de um esquecimento. In BESSA FREIRE, José Ribamar \& Rosa, Maria Carlota (Orgs.) Línguas gerais: política linguística e catequese na América do Sul no período colonial, 195-207. Rio de Janeiro: EDUERJ.

Atlântica.

2004. Rio Babel: a história das línguas na Amazônia. Rio de Janeiro:

2010. As relações históricas entre o português e o nheengatu nos universos urbano e rural da Amazônia. In Noll, Volker \& Dietrich, Wolf (Orgs.) O português e o tupi no Brasil, 183-209. São Paulo: Contexto.

CARNEIRO RIBEIRO, Ernesto. Serões Gramaticais. Bahia: Livraria Catilina, 1890.

CASCAIS, Antônio Fernando. Paixão, morte e ressurreição do sujeito em Foucault. Comunicação e Linguagens. Lisboa: Cosmos, n.19, 1993. p.77-117.

CÂMARA DOS DEPUTADOS. Projeto de Lei N. ${ }^{\circ}$ 3.074-A, de 2019 (Do Sr. Dagoberto Nogueira) Cooficialização das Línguas indígenas nos municípios brasileiros que possuem comunidades indígenas. Brasília, 2019. Disponível em: $<$ https://www.camara.leg.br/proposicoesWeb/prop_mostrarintegra;jsessionid=E739 2611A9A38ACDE22FE3967D6DB4F1.proposicoesWebExterno1?codteor=1751325\&f ilename=PL+3074/2019 > Acessado em 10/10/2020, às 11h.

DE FRANCO, Antônio. Método de Caligrafia De Franco - Sempre é tempo... De Franco: São Paulo, 1928.

FARIA FILHO, Luciano Mendes de. Cultura e prática escolares: escrita, aluno e corporeidade. Cadernos de Pesquisa, n.103, mar. 1998, p. 136-149.

FERREIRA COELHO, Olga; GABRIEL DANNA, Stela Maris; POLACHINI, Bruna Soares. O português do Brasil em gramáticas brasileiras do século XIX. Confluência, n. 46. Rio de Janeiro, $1^{\mathrm{o}}$ semestre de 2014. Disponível em: https://pt.scribd.com/document/387524723/O-portugues-brasileiro-em-gramaticasbrasileiras-do-seculo-XIX-Olga-Coelho-pdf. Acesso em: 20/12/2020.

FOUCAULT, Michel. Sobre a História da Sexualidade. In: Microfísica do poder. Org. e trad. Roberto Machado. 17. ed. Rio de Janeiro: Graal, 1979a, p. 243-276.

. A arqueologia do Saber. Rio de Janeiro: Forense Universitária, 2008. . A Microfísica do Poder. São Paulo: Graal, 2007.

. A Ordem do Discurso. São Paulo: Edições Loyola, 1996.

A verdade e as formas jurídicas. Rio de Janeiro: Nau Editora, 2003.

. Em defesa da sociedade. São Paulo: Martins Fontes, 1999. 
Nietzsche, a genealogia e a história. In: Arqueologia das Ciências e

História dos Sistemas de Pensamento. Org. de Manoel Barros da Motta. Rio de Janeiro: Forense Universitária, 2000, p. 260-281. Coleção Ditos \& Escritos, vol. 2.

Segurança, Território, População. Curso ministrado no Collège de France (janeiro a abril 1978). São Paulo: Martins Fontes, 2007.

Nascimento da biopolítica, Curso ministrado no Collège de France (1978/1979). São Paulo: Martins Fontes, 2008.

GOMES CARDIM, Carlos Augusto. Tradições Nacionaes. Episódios Históricos e Brasileiros Notáveis. São Paulo: Typographia Augusto Siqueira, 1916.

GREGOLIN, Maria do Rosario. As fadas tinham ideias: procedimentos discursivos e produção social de sentidos. Tese de Doutoramento. Universidade Estadual Paulista, 1988.

O dispositivo escolar republicano na paisagem das cidades brasileiras: enunciados, visibilidades, subjetividades. Revista Moara, Belém, n. 43, p. 6-25, jan.jun. 2015. Disponível em: 〈http://dx.doi.org/10.18542/moara.v1i43.2633〉. Acesso em: 22/10/2002, às $10 \mathrm{~h}$.

GREGOLIN, Maria do Rosário; NEVES CORRÊA, Maurício. Web série Análise do Discurso com Michel Foucault | Ep. 02 Os dispositivos. Vídeo Educacional. Duração: 27:35. Araraquara/Belém: Unesp/Universidade Federal do Pará, 2016. Disponível em: < https://www.youtube.com/watch?v=IpMURaG9hYc\&t=41s > Acessado em $15 / 08 / 2020$, às $10 \mathrm{~h}$.

GREGOLIN, Maria do Rosário; NEVES CORRÊA, Maurício. Web série Análise do Discurso com Michel Foucault | Ep. 03 O dispositivo escolar. Vídeo Educacional. Duração: 47:16. Araraquara/Belém: Unesp/Universidade Federal do Pará, 2017. Disponível em: < https://www.youtube.com/watch?v=TdVYvrh-JfA\&t=397s > Acessado em 01/11/2020, às 9h.

KAMBEBA, Márcai. Ay kakyri tama/ Eu moro na cidade. São Paulo: Pólen, 2018.

LEITE, Fabiana Raquel. A Língua Geral Paulista e o "Vocabulário da Língua Geral Brasílica". Campinas: Unicamp. Dissertação de Mestrado, 2013. Disponível em: http://repositorio.unicamp.br/jspui/bitstream/REPOSIP/268989/1/Leite_FabianaRaquel_ M.pdf. Acesso em: 18/12/2020.

LIMA, Ivana Stolze; DO CARMO, Lara (org.). História Social da Língua Nacional. Rio de Janeiro: Casa de Rui Barbosa, 2008. Disponível em: http://www.casaruibarbosa.gov.br/dados/DOC/artigos/aj/FCRB_Historia_social_da_lingua_nacional.pdf. Acesso em: 20/12/2020.

LISBÔA, Flávia Marinho; NEVES, Ivânia dos Santos; GREGOLIN, Maria do Rosário; BARACUHY, Maria Regina; NEVES CORREAA, Maurício; WITZEL; Denise Gabriel; CARVALHO, Vívian de Nazareth Santos; SANTOS, Rodrigo Wallace Cordeiro dos. Gedaicast 4 - A Governamentalidade e o Governo da Língua. Vídeo Educacional. Duração: 1:42:40. Belém: Universidade Federal do Pará, 2020. Disponível em: < https://www.youtube.com/watch?v=-PDs6rFczHo > Acessado em 10/11/2020, às 11h.

MENDONÇA, Marcos Carneiro de. A Amazônia na era pombalina - Tomo III. Brasília: Senado Federal, conselho editorial, 2005. 
NEVES, Ivânia. A invenção do índio e as narrativas orais Tupi. 158f. Tese (Doutorado em Linguística) - Instituto de Estudos da Linguagem, Universidade Estadual de Campinas, Campinas, 2009.

EtniCidades: os 400 anos de Belém e a presença indígena. Revista Moara, n. 43, jan.-jul, 2015.

Fraturas contemporâneas de histórias indígenas em Belém: sobre mármores

e grafites. Revista Maracanan, maio-ago 2020.

PACHECO DA SILVA JÚNIOR, Manuel e LAMEIRA DE ANDRADE. Grammatica da Lingua Portugueza para uso dos gymnasios, lyceus e escolas normaes. Rio de Janeiro: J. G. De Azevedo, 1887.

PRADO FILHO, Kleber. A genealogia como método histórico de análise de práticas e relações de poder. Revista de Ciências Humanas, Florianópolis, v. 51, n. 2, p. 311327, jul-dez 2017.

PINTO, Edith Pimentel. O Português do Brasil: textos críticos e teóricos, 1 1820/1920, fontes para teoria e a história. São Paulo: Edusp, 1978.

RIBEIRO, João. Grammatica Portugueza: $3^{\mathbf{o}}$ anno. $3^{\mathrm{a}}$ edição. Rio de Janeiro: Livraria Clássica de Alves\& C.,1889[1887].

SCHWARCZ, Lília M.; STARLING, Heloisa M. Brasil: uma biografia. São Paulo: Companhia das Letras, 2018.

VARNHAGEN, Francisco Adolfo de. História geral do Brasil - Tomo Primeiro. Rio de Janeiro: E. e H. Laemmert, 1854.

História geral do Brasil - Tomo segundo. Rio de Janeiro: E. e H. Laemmert. Madrid: Imprensa de J. del Rio, 1857.

VIDAL, Diana Gonçalves. Da caligrafia a escrita: experiências escolanovistas com caligrafia muscular nos anos 30. In: Revista da Faculdade de Educação, São Paulo, USP v.24, n.1, jan./jun. 1998, p. 126-140. 